\title{
Antibacterial and antitumor activity of the species Prunella vulgaris $L$.
}

\author{
Alexandra Groșan ${ }^{1}$, Camil- Eugen Vari ${ }^{1}$, Ruxandra Ștefănescu ${ }^{2}$, Corina Danciu ${ }^{3}$, \\ Ioana Zinuca Pavel ${ }^{3}$, Cristina Dehelean ${ }^{4}$, Adrian $\mathrm{Man}^{5 *}$, Remona Eliza David ${ }^{6}$, \\ Laurian Vlase ${ }^{7}$, Lucia Daniela Muntean ${ }^{8}$
}

1. Department of Pharmacology and Clinical Pharmacy, Faculty of Pharmacy, George Emil Palade

University of Medicine, Pharmacy, Science, and Technology of Târgu Mureș, Romania

2. Department of Pharmacognosy and Phytotherapy, Faculty of Pharmacy, George Emil Palade

University of Medicine, Pharmacy, Science, and Technology of Târgu Mureș, Romania

3. Department of Pharmacognosy, Victor Babeş University of Medicine and Pharmacy, Timişoara,

Romania

4. Department of Toxicology, Victor Babeş University of Medicine and Pharmacy, Timişoara, Romania

5. Department of Microbiology, Faculty of Medicine, George Emil Palade University of Medicine,

Pharmacy, Science, and Technology of Târgu Mureș, Romania

6. Departament of Laboratory Medicine, George Emil Palade University of Medicine, Pharmacy,

Science, and Technology of Târgu Mureș, Romania

7. Department of Pharmaceutical Technology and Biopharmaceutics, Iuliu Hațieganu University of

Medicine and Pharmacy, Cluj-Napoca, Romania

8. Department of Analytical Chemistry and Drug Analysis, Faculty of Pharmacy, George Emil Palade

University of Medicine, Pharmacy, Science, and Technology of Târgu Mureș, Romania

\begin{abstract}
Background: Prunella vulgaris L., known as self-healing herb, is a widely spread species in the spontaneous flora with beneficial effects on human health, a fact proven in particular by Asian researchers. The aim of this study was to evaluate the antitumor activity and the antibacterial effect on different bacterial strains, including multidrug-resistant ones, depending on the type of solvent used (aqueous, hydroalcoholic), the plant product taken into consideration (spike inflorescence, leaf), its quantity and the concentration of active principles. Material and method: For screening of antimicrobial susceptibility, both minimum inhibitory concentration and minimum bactericidal concentration were determined on Escherichia coli, Klebsiella pneumoniae, Providencia stuartii, Pseu-
\end{abstract}

\footnotetext{
* Corresponding author: Adrian Man, Department of Microbiology, George Emil Palade University of
} Medicine, Pharmacy, Science, and Technology of Târgu Mureș, Romania. E-mail: adrian.man@umfst.ro 
domonas aeruginosai, and methicillin-resistant Staphylococcus aureus species, including reference strains and hospital strains. Leaves and flower extracts (aqueous and 70\% methanolic) were first assessed, and the one with the best antibacterial potential was further tested as a concentrated extract. The antitumor activity was determined on MDA-MB-231 breast adenocarcinoma cells and on a non-tumor cell line, MCF-10A breast epithelial cells by means of Alamar blue technique and Scratch assay. Results: Inflorescence extracts showed better bacteriostatic effects than leaf extracts on most bacteria, in both aqueous and hydroalcoholic extracts. The concentrated extract of spike inflorescence showed measurable activity with good effects on Gram-positive bacteria, but also on multidrug-resistant Gram-negative ones. The 70\% methanolic extract of the species Prunella vulgaris L. (spike inflorescence) demonstrated a concentration-dependent cytotoxic and anti-migratory activity on MDA-MB-231 breast cancer cells, while affecting the non-tumor cell line less. Conclusions: The results suggest that Prunella vulgaris extracts present antibacterial potential in the complementary treatment of multidrug-resistant infections. The extract from the spike inflorescence of Prunella vulgaris L. produced a dose and time-dependent reduction in cell viability and migration, eliciting a stronger effect on the breast adenocarcinoma cell line.

Keywords: Prunella vulgaris L., antibacterial, antitumor

Received: 20 th May 2020; Accepted: $21^{\text {st }}$ July 2020; Published: $30^{\text {th }}$ August 2020

\section{Introduction}

The increased interest for the species Prunella vulgaris L., commonly used in traditional medicine in some countries in Europe, Asia, America, and Australia, has contributed to the intensification of phytochemical and pharmacological studies in order to identify bioactive compounds, justify the use in traditional medicine and develop standardized extracts with constant, reproducible effects $(1,2)$. Prunella vulgaris L. grows in the spontaneous flora of Romania in humid places, fields, meadows, grasslands, unpopulated areas, and unpaved lawns, both in the sun and in the shade (3). The species under consideration presents an important source of active principles with numerous pharmacological actions. Prunella vulgaris L. has multiple therapeutic benefits including antimicrobial and antitumor action (46).

Studies on the action of aqueous, alcoholic and hydroalcoholic extract have highlighted the antimicrobial, antifungal, and antiviral properties. The aqueous and hydroalcoholic extract of the species Prunella vulgaris L. revealed the anti- bacterial effect on Escherichia coli, Klebsiella pneumoniae, Proteus vulgaris, and on different Staphylococcus species (7-9). The methanolic extract of Prunella vulgaris L. (root) has demonstrated in vitro antiproliferative activity on different breast cancer cell lines: MCF-7, MDA-MB231BO. The study conducted by Roh et al. on MCF-7 cell line demonstrated that cell growth was stopped, the cell apoptosis was induced and the pathway PI3K/ AKT was modulated, which is an important target for anticancer agents as it is an activated pathway in cancer cells, especially in ovarian, breast, and urothelial cancers. The results of the aqueous extract of the spiciform inflorescences $(10 \% \mathrm{~V} / \mathrm{V})$ indicated an increased action on skin, maintaining the skin integrity by inhibiting 11ß-hydroxysteroid dehydrogenase 1 (11ß - HSD1) activation, an enzyme that helps skin cells synthesize cortisol) $(4,10,11)$. Considering the favorable biological effects, these natural extracts could be alternative sources of compounds that can be used in infection control. Currently there are reported studies conducted mainly with the herbal drugs collected from China, Czech Republic, South Korea, etc. However, 
to our knowledge, no studies were conducted with the herbal drug collected in Romania. As it is known, climatic factors and geographical conditions can exert a high influence upon the chemical composition of plants. Considering that differences between the same species from different regions of the globe are to be expected, the present research aimed to investigate the phytochemical profile and pharmacological actions of Prunella vulgaris L. from Romania and to compare the outcome with results from other studies conducted on the same species harvested from various world regions.

\section{Materials and Methods}

\section{HPLC/MS analysis}

Sample preparation

Two grams of crushed spike inflorescence were mixed with either $100 \mathrm{~mL}$ of $70 \%$ methanolic solution or with $100 \mathrm{~mL}$ ultrapure water. The sample was placed in an ultrasonic bath at $40^{\circ} \mathrm{C}$ for 60 minutes. After cooling, the extracts were filtered and stored at $-50^{\circ} \mathrm{C}$ until analysis.

\section{Chromatographic and mass spectrometry con- ditions}

Rosmarinic acid was identified and quantified using a validated LC-MS analytical method described by Vlase et al $(12,13)$. The equipment that was used was an Agilent 1100 HPLC Series system (Agilent, Santa Clara, CA, USA) equipped with a binary pump, auto sampler, column thermostat (set at $48^{\circ} \mathrm{C}$ ), and UV detector. The mass spectrometer was an Agilent Ion Trap 1100 SL (LC/MSD Ion Trap VL, Agilent, Santa Clara, CA, USA) equipped with electrospray ionization (ESI) or atmospheric pressure chemical ionization (APCI). The injection volume was $3 \mu \mathrm{L}$ and the flow rate was $1 \mathrm{~mL} / \mathrm{min}$. Compound separation was performed on a reverse-phase analytical column (Zorbax SB-C18 100 X $3.0 \mathrm{~mm}$ i.d., $3.5 \mu \mathrm{m}$ particle). The elution solvents were $1 \mathrm{mM}$ ammonium acetate (A) and acetonitrile (B) in water. Samples were eluted according to a linear gradient: $0-3.3 \mathrm{~min}, 5-25 \%$ B; 3.3-3.4 min, 25-90\% B; 3.4-3.8 $\mathrm{min}, 90 \%$ isocratic B; 3.8-3.9 min, 90-5\% B. The MS with ESI source operated in negative ionization mode and was set for fragmentation and isolation of deprotonated rosmarinic acid molecule with $\mathrm{m} / \mathrm{z}$ $=359$. The quantification of this bioactive compound was assessed based on the deprotonated molecule.

The calibration curve of rosmarinic acid was performed in the concentration range of 0.095 $1.520 \mu \mathrm{g} / \mathrm{ml}$. All solutions were prepared in ultrapure water.

\section{Antibacterial effect}

The inhibitory (MIC) and bactericidal (MBC) activity of the extracts were assessed on seven bacterial strains which are representative for Gram-positive (Staphylococcus aureus ATCC 43300 - MRSA, Staphylococcus aureus ATCC 25923 - MSSA) and Gram-negative (Klebsiella pneumoniae ATCC13883, Escherichia coli ATCC25922, Pseudomonas aeruginosa ATCC27853, multidrug resistant Klebsiella pneumoniae, multidrug resistant Providencia stuartii) bacteria, including reference strains and multidrug-resistant clinical isolates (Table 1).

The plant extracts were sterilized by filtration using $0.45 \mu$ Whatman $25 \mathrm{~mm}$ syringe filters (GE Healthcare).

The MIC was assessed by microdilution method, based on CLSI 2018 standard $11^{\text {th }}$ edition, document M07 (14). Shortly, in a sterile 96-well plate, each well of the first column was filled with $200 \mu \mathrm{l}$ of each plant extract. From each extract, $100 \mu 1$ were subsequently diluted with $100 \mu 1$ sterile water in the remaining wells from each row. Each well of the plate was then filled with a bacterial inoculum (approximately $10^{\wedge} 4 \mathrm{CFU} /$ $\mathrm{ml}$ ) in 2x concentrated Muller-Hinton broth. One plate was prepared for each bacterial strain. Pos- 
Table 1. Characteristics of the clinical isolates

\begin{tabular}{llll}
\hline Strain & Source & Susceptible & Resistant \\
\hline $\begin{array}{l}\text { Klebsiella } \\
\text { pneumoniae }\end{array}$ & Respiratory & Tigecycline, & Ticarcillin/clavulanic acid, Piperacillin, \\
& tract secretion & Trimethoprim & Cefuroxime, Cefixime, Ceftriaxone, Cefepime, \\
& & Aztreonam, Meropenem, Levofloxacin, \\
& & Moxifloxacin, Minocycline \\
\hline $\begin{array}{ll}\text { Providencia } \\
\text { stuartii }\end{array}$ & Respiratory & Aztreonam & Ticarcillin/clavulanic acid, Piperacillin, \\
& tract secretion & & Ceftazidime, Cefepime, Aztreonam, Imipenem, \\
& & Meropenem, Amikacin, Gentamicin, Tobramycin, \\
& & Ciprofloxacin, Minocycline, Trimethoprim/ \\
& & sulfamethoxazole \\
\hline
\end{tabular}

itive and negative growth controls were used for all bacteria. The plates were incubated at $35^{\circ} \mathrm{C}$ overnight. The MICs were interpreted by visual reading in the last well that did not show bacterial growth.

The MBCs were assessed by inoculating $1 \mu \mathrm{l}$ from the last wells that did not show bacterial growth in the MIC plate in the wells of a new plate that contained $100 \mu 1$ Muller-Hinton broth/ well. The MBCs were interpreted similarly as for MIC, by visual reading, in the last well that did not show bacterial growth.

\section{In vitro antitumoral effects of Prunella vulgar- is extract}

\section{Cell culture}

MDA-MB-231 - human breast adenocarcinoma cell line (ATCC $\AA$ HTB-26 ${ }^{\mathrm{TM}}$ ) and MCF$10 \mathrm{~A}$ - non-tumorigenic breast epithelial cell line (ATCC ${ }^{\circledR}$ CRL-10317 ${ }^{\mathrm{TM}}$ ) were purchased from the American Type Culture Collection (ATCC). MDA-MB-231 cells were cultured in high glucose Dulbecco's Modified Eagle's Medium (DMEM; Sigma-Aldrich), supplemented with $10 \%$ fetal bovine serum (FBS; Gibco, ThermoFisher Scientific) and 1\% Penicillin/ Streptomycin mixture (Pen/Strep, 10,000 IU/ml; Sigma-Aldrich). MCF-10A cells were cultured in 1:1 mixture DMEM:F-12 medium (ATCC) supplemented with $20 \mathrm{ng} / \mathrm{mL}$ epidermal growth factor (EGF; Gibco, ThermoFisher Scientific),
$500 \mathrm{ng} / \mathrm{mL}$ hydrocortisone (Sigma-Aldrich), $0.01 \mathrm{ng} / \mathrm{mL}$ insulin (Sigma-Aldrich), $500 \mathrm{ng} / \mathrm{mL}$ hydrocortisone (Sigma-Aldrich), 5\% FBS and $1 \%$ Pen/Strep mixture. The culture plates were kept in standard conditions, $37^{\circ} \mathrm{C}$ in a humidified atmosphere containing $5 \% \mathrm{CO}_{2}$ and passaged three times a week.

\section{Alamar blue assay}

Alamar blue is a technique used for cell viability assessment. The principle of the assay consists of the ability of metabolically active cells (viable cells) to reduce resazurin (the dark blue compound) to resorufin (the pink compound with an intense fluorescence). The assay was conducted as previously described (15). Briefly, a number of $1 \times 10^{4} \mathrm{cells} /$ well were plated in 96-well plates and allowed to adhere overnight. Afterwards, the cells were stimulated with different concentrations $(1,10,50,100,250,500$ and $750 \mu \mathrm{g} /$ $\mathrm{mL}$ ) of Prunella vulgaris extract (spike inflorescence) and incubated for 24,48 , and $72 \mathrm{~h}$. Control cells were stimulated with the same amount of dimethyl sulfoxide (DMSO), the solvent used for the preparation of the stock solution. After the incubation period, Alamar blue $(20 \mu \mathrm{L} /$ well - $10 \%$ of the volume of cell culture medium) was added and the cells were incubated at $37^{\circ} \mathrm{C}$ for $3 \mathrm{~h}$. After that, the absorbance was measured spectrophotometrically at 570 and $600 \mathrm{~nm}$ with a microplate reader (xMark Microplate Spectrophotometer, Bio-Rad). 
Scratch assay

This in vitro method evaluates the anti-migratory potential of Prunella vulgaris extract (spike inflorescence) on the two cell lines. The assay was conducted as previously described (16). Briefly, a number of $2 \times 10^{5}$ cells/ well were cultured in 12-well plates until $90 \%$ confluence was reached. A sterile pipette tip was used to draw scratches on well-defined zones of the cells monolayer and the detached cells were removed by washing with phosphate-buffered saline (PBS) prior to stimulation. Cells were stimulated with different concentrations $(1,10,50,100$ and $250 \mu \mathrm{g} / \mathrm{mL})$ of Prunella vulgaris extract (spike inflorescence). Images of the cells in culture were taken at the starting point of the experiment $(0 \mathrm{~h})$ and after $24 \mathrm{~h}$ and were compared to Control cells (cells stimulated with the solvent DMSO) using Olympus IX73 inverted microscope provided with DP74 camera (Olympus, Tokyo, Japan). Cell growth analysis was evaluated with cell Sense Dimension software. The scratch closure rate was calculated according to the formula (15):

$$
\text { Scratch closure rate }=\left[\frac{A_{t 0}-A_{t}}{A_{t 0}}\right] * 100
$$

where: $A_{t 0}$ is the scratch area at time $0 ; A_{t}$ is the scratch area at $24 \mathrm{~h}$.

\section{Statistical analysis}

The data were expressed as mean \pm standard deviation (SD). One-way ANOVA test followed by Dunnett's multiple comparison test was used for comparison among the groups for the in $v i$ tro antitumor effects. A $p$ value of $\leq 0.05$ was considered to be of statistical significance. For the statistical analysis GraphPad Prism 5 was used.

\section{Results}

\section{HPLC/MS analysis}

An HPLC-MS method was used for the quantification of rosmarinic acid in the extracts from $P$. vulgaris spike.

The recorded full-scan mass spectrum of a rosmarinic acid solution is shown in figure 1. The expected ion, according to the molecular mass of the rosmarinic acid $(M=360.2)$ and depending on the ionization mode (negative) would be the ion with $m / z 359$, corresponding to the deprotonated molecule.

In order to increase the selectivity of the LC/MS method, fragmentation of the characteristic rosmarinic acid ion $(\mathrm{m} / \mathrm{z} 359)$ was performed and the MS spectrum was recorded (Figure 2).

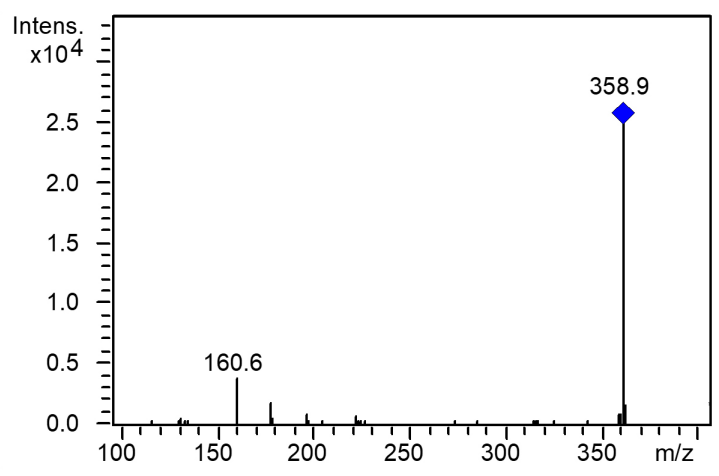

Fig. 1. Full-scan spectrum of rosmarinic acid in mobile phase

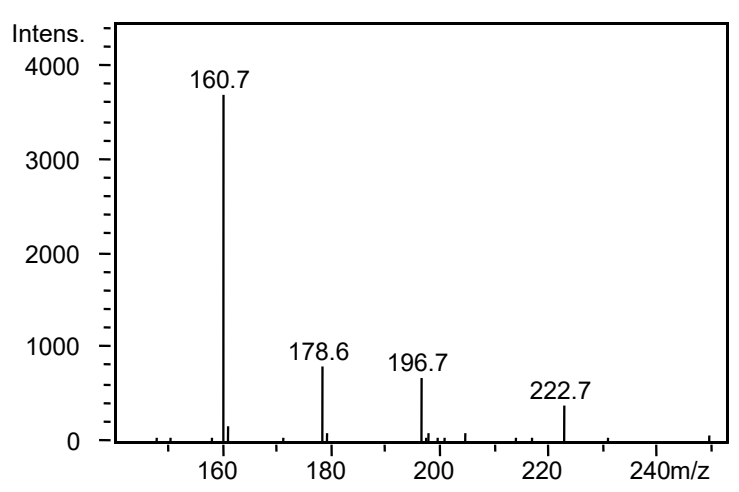

Fig. 2. MS/MS spectrum of rosmarinic acid in mobile phase 
By fragmentation, the rosmarinic acid is disintegrated into four main fragments, with $\mathrm{m} / \mathrm{z}$ $160.7,178.6,196.7$ respectively 222.7 .

Following the HPLC-MS determination, 27.69 $\mu \mathrm{g}$ rosmarinic acid / $\mathrm{mL}$ (1.38 $\mathrm{mg}$ rosmarinic acid/g dry material plant) was obtained in the aqueous extract of the crushed spike, and 97.19 $\mu \mathrm{g}$ rosmarinic acid / $\mathrm{mL}$ (4.85 $\mathrm{mg}$ rosmarinic acid/g dry material plant) in the $70 \%$ methanolic extract.

\section{Antibacterial effect}

We tested the antibacterial activity of two different Prunella extracts: aqueous solution, methanolic extract and concentrated aqueous solution after initial extraction with methanol. Leaves and flower extracts were first assessed and the one with the best antibacterial potential was further used as concentrated extract. No significant differences were found between leaf and flower aqueous extracts, both types presenting low antibacterial effect, with inhibitory concentrations at values ranging from 25 to more than $50 \mathrm{mg} / \mathrm{ml}$. Both Gram-positive and Gram-negative bacteria presented a quasi-equal behavior to the tested substances. The methanolic extracts presented the best antibacterial effect, with MICs as low as 6.25 or $12.5 \mathrm{mg} / \mathrm{ml}$, but these values were also observed for $70 \%$ alcohol. Of the Gram-negative bacteria, the most susceptible were the non-glucose-fermenter Pseudomonas aeruginosa and the clinical isolate of Klebsiella pneumoniae with MICs of 6.25 and $12.5 \mathrm{mg} / \mathrm{ml}$ respectively. Due to the low concentration of active substance in aqueous and methanolic extracts, their real MICs could not be determined, most values being of more than $50 \mathrm{mg} / \mathrm{ml}$. Instead, the concentrated extract presented quantifiable activity, with good effect on Gram-positive bacteria. Moreover, in concentrated extract, the bactericidal effect was found to be at the same concentration as the inhibitory effect (MBC=MIC). Of the Gram-negative bacteria, Klebsiella pneumo- niae was the least susceptible. It is known that Klebsiella species present a protective mucopolysaccharidic capsule, which makes this bacterial species resistant to several environmental factors, including antibacterial agents $(17,18)$. Details of the antibacterial activity of the tested extracts can be found in Table 2 .

If reported to the antimicrobial effect of $70 \%$ methanol, the results show a lower effect for leaf extracts than for flower extracts. Nevertheless, the overall effects were equal with that of the $70 \%$ methanol, with a single exception: against MSSA, where both the leaf and flower extracts were more efficient. A sub-unitary index obtained by dividing the MIC/MBC of the extract to the MIC/MBC of methanol equals a better effect of the extract than the methanol alone (Table 3).

The flower extracts presented better bacteriostatic effect than the leaf extracts on most bacteria, both the aqueous and methanolic extracts. A sub-unitary index obtained by dividing the $\mathrm{MIC} /$ $\mathrm{MBC}$ of the flower extract to the MIC/MBC of the leaf extract equals a better effect of the first one (Table 4).

\section{In vitro cytotoxic and anti-migratory effects of Prunella vulgaris extract}

Cells viability assessment

Prunella vulgaris extract (spike inflorescence) was tested for its cytotoxic effects on MDAMB-231 - breast adenocarcinoma cells and on healthy MCF-10A breast epithelial cells at different incubation periods (24h, 48h, 72h). A Control group - cells stimulated with the solvent DMSO was also included. Figure 3 depicts the effect of the extract on the non-tumorigenic cell line. Results have shown that stimulation with Prunella vulgaris extract induced a dose and time dependent decrease in MCF-10A cells viability, at the highest tested concentrations, namely 500 and $750 \mu \mathrm{g} / \mathrm{mL}$. At doses ranging between 1-250 $\mu \mathrm{g} /$ $\mathrm{mL}$, the extract did not affect significant MCF- 
Table 2. Bacterial minimum inhibitory (MIC) and bactericidal (MBC) concentrations $(\mathrm{mg} / \mathrm{ml})$ of the extracts.

\begin{tabular}{|c|c|c|c|c|c|c|c|c|c|c|c|c|}
\hline \multirow{2}{*}{\multicolumn{2}{|c|}{ Strain }} & \multicolumn{4}{|c|}{ Aqueous extracts } & \multicolumn{4}{|c|}{ Methanolic extracts } & \multirow{2}{*}{\multicolumn{2}{|c|}{ Methanol }} & \multirow{2}{*}{$\begin{array}{c}\begin{array}{c}\text { Concentrated } \\
\text { extract }\end{array} \\
\text { Flowers } \\
\end{array}$} \\
\hline & & \multicolumn{2}{|c|}{ Leaves } & \multicolumn{2}{|c|}{ Flowers } & \multicolumn{2}{|c|}{ Leaves } & \multicolumn{2}{|c|}{ Flowers } & & & \\
\hline & & $\stackrel{U}{\Sigma}$ & $\sum_{\sum}^{U}$ & $\stackrel{U}{\Sigma}$ & $\sum_{i}^{e}$ & $\stackrel{U}{\Sigma}$ & $\stackrel{u}{\sum}$ & $\stackrel{U}{\Sigma}$ & $\sum_{\Sigma}^{U}$ & $\stackrel{U}{\Sigma}$ & $\sum^{U}$ & 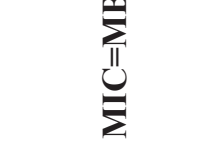 \\
\hline \multirow{5}{*}{ 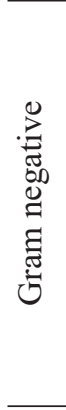 } & $\begin{array}{l}\text { Klebsiella pneumoniae } \\
\text { MDR }\end{array}$ & $>50$ & $>50$ & 50 & $>50$ & 25 & 50 & 12.5 & 25 & 12.5 & 25 & 333.5 \\
\hline & $\begin{array}{c}\text { Klebsiella pneumoniae } \\
\text { ATCC13883 }\end{array}$ & $>50$ & $>50$ & 50 & $>50$ & 25 & 50 & 25 & 25 & 12.5 & 25 & 333.5 \\
\hline & $\begin{array}{c}\text { Providencia stuartii } \\
\text { MDR }\end{array}$ & $>50$ & $>50$ & 50 & $>50$ & 50 & 50 & 25 & 25 & 12.5 & 25 & 83.4 \\
\hline & $\begin{array}{c}\text { Escherichia coli } \\
\text { ATCC25922 }\end{array}$ & $>50$ & $>50$ & $>50$ & $>50$ & 50 & 50 & 25 & 25 & 12.5 & 25 & 83.4 \\
\hline & $\begin{array}{c}\text { Pseudomonas aerugino- } \\
\text { sa ATCC27853 }\end{array}$ & $>50$ & $>50$ & 25 & $>50$ & 12.5 & 50 & 6.25 & 25 & 6.25 & 25 & 166.8 \\
\hline \multirow{2}{*}{ 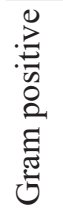 } & MRSA ATCC 43300 & $>50$ & $>50$ & $>50$ & $>50$ & 25 & 25 & 25 & 25 & 25 & 25 & 41.7 \\
\hline & MSSA ATCC 25923 & $>50$ & $>50$ & 50 & $>50$ & 25 & 25 & 25 & 25 & 25 & 50 & 41.7 \\
\hline
\end{tabular}

Table 3. Normalized indexes of MIC/MBC against alcohol

\begin{tabular}{|c|c|c|c|c|c|}
\hline \multirow{2}{*}{ Strain } & & \multicolumn{2}{|c|}{ MICs for methanolic extracts } & \multicolumn{2}{|c|}{ MBCs for methanolic extracts } \\
\hline & & Leaf & Flower & Leaf & Flower \\
\hline \multirow{5}{*}{ 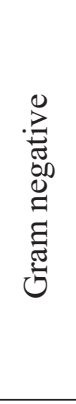 } & $\begin{array}{c}\text { Klebsiella pneumoniae } \\
\text { MDR }\end{array}$ & 2 & 1 & 2 & 1 \\
\hline & $\begin{array}{c}\text { Klebsiella pneumoniae } \\
\text { ATCC } 13883\end{array}$ & 2 & 2 & 2 & 1 \\
\hline & $\begin{array}{c}\text { Providencia stuartii } \\
\text { MDR }\end{array}$ & 4 & 2 & 2 & 1 \\
\hline & $\begin{array}{l}\text { Escherichia coli } \\
\text { ATCC } 25922\end{array}$ & 4 & 2 & 2 & 1 \\
\hline & $\begin{array}{c}\text { Pseudomonas aeruginosa } \\
\text { ATCC } 27853\end{array}$ & 2 & 1 & 2 & 1 \\
\hline \multirow{2}{*}{ 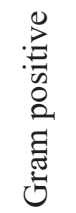 } & MRSA ATCC 43300 & 1 & 1 & 1 & 1 \\
\hline & MSSA ATCC 25923 & 1 & 1 & 0.5 & 0.5 \\
\hline
\end{tabular}

Index $<1-$ low MIC/MBC (better effect than methanol);

Index $1-\mathrm{MIC} / \mathrm{MBC}$ equal with alcohol;

Index $>1$ - high MIC/MBC (lower effect than methanol); 
Table 4. Indexes of MIC/MBC for flower extracts reported to leaf extracts

\begin{tabular}{|c|c|c|c|c|c|}
\hline & \multirow[b]{2}{*}{ Strain } & \multicolumn{2}{|c|}{ MIC } & \multicolumn{2}{|c|}{ MBC } \\
\hline & & $\begin{array}{c}\text { Flower/Leaf } \\
\text { Aqueous extract }\end{array}$ & $\begin{array}{c}\text { Flower/Leaf } \\
\text { Methanolic extract }\end{array}$ & $\begin{array}{c}\text { Flower/Leaf } \\
\text { Aqueous extract }\end{array}$ & $\begin{array}{c}\text { Flower/Leaf } \\
\text { Methanolic extract }\end{array}$ \\
\hline \multirow{5}{*}{ 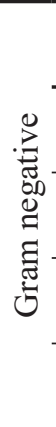 } & $\begin{array}{c}\text { Klebsiella pneumoniae } \\
\text { MDR }\end{array}$ & $>1$ & 0.5 & $>1$ & 0.5 \\
\hline & $\begin{array}{c}\text { Klebsiella pneumoniae } \\
\text { ATCC } 13883\end{array}$ & $>1$ & 1 & $>1$ & 0.5 \\
\hline & $\begin{array}{c}\text { Providencia stuartii } \\
\text { MDR }\end{array}$ & $>1$ & 0.5 & $>1$ & 0.5 \\
\hline & $\begin{array}{c}\text { Escherichia coli ATCC } \\
25922\end{array}$ & $>1$ & 0.5 & $>1$ & 0.5 \\
\hline & $\begin{array}{c}\text { Pseudomonas aeruginosa } \\
\text { ATCC } 27853\end{array}$ & $>1$ & 0.5 & $>1$ & 0.5 \\
\hline \multirow{2}{*}{ 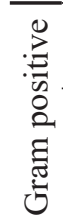 } & $\begin{array}{c}\text { MRSA } \\
\text { ATCC 43300 } \\
\end{array}$ & $>1$ & 1 & $>1$ & 1 \\
\hline & $\begin{array}{c}\text { MSSA } \\
\text { ATCC } 25923\end{array}$ & $>1$ & 1 & $>1$ & 1 \\
\hline
\end{tabular}

Index $<1$ - low MIC/MBC for flower (better effect than leaf); Index 1 - equal MIC/MBC for flower and leaf; Index $>1-$ high MIC/MBC for flower (lower effect than leaf);

$10 \mathrm{~A}$ breast cells viability regardless of the incubation period.

Figure 4 describes the effect of Prunella vulgaris extract (spike inflorescence) on the selected breast adenocarcinoma cell line (MDA-MB-231). One can observe that at low concentrations ( 1 and 10 $\mu \mathrm{g} / \mathrm{mL})$, the extract did not affect cell viability. By increasing the concentration, a significant dose and time dependent decrease in tumor cell viability was noticed, with the most potent effect obtained at $72 \mathrm{~h}$ post-stimulation. Thus, it can be concluded that starting from the concentration of $250 \mu \mathrm{g} / \mathrm{mL}$ Prunella vulgaris extract presents selectivity against the cancer cell lines.

\section{Evaluation of the anti-migratory potential}

In order to evaluate the anti-migratory effect of Prunella vulgaris extract (spike inflorescence) the scratch assay technique was used. Breast cancer cells were stimulated with different concentrations of the extract and compared to Control cells (cells stimulated with the solvent DMSO).
The two highest concentrations of the extract (500 and $750 \mu \mathrm{g} / \mathrm{mL}$ ) were not tested due to the fact that the percent of viable cells was very low. At the lowest doses tested ( 1 and $10 \mu \mathrm{g} / \mathrm{mL}$ ), the extract stimulated cell migration (scratch closure rate $100 \%$ ), but by increasing the concentration $(50,100$ and $250 \mu \mathrm{g} / \mathrm{mL})$ a significant reduction in tumor cell migration was obtained; scratch closure rates were $73.9 \%(50 \mu \mathrm{g} / \mathrm{mL}), 0.1 \%$ (100 $\mu \mathrm{g} / \mathrm{mL})$ and $-1.9 \%(250 \mu \mathrm{g} / \mathrm{mL})$. Moreover, at $24 \mathrm{~h}$ after stimulation, at the highest tested doses (100 and $250 \mu \mathrm{g} / \mathrm{mL}$ ) changes in tumor cell morphology can be observed - cells display round shape and some of them are detached from the plate, indicating that Prunella vulgaris extract affects breast adenocarcinoma cells.

\section{Discussions}

According to the scientific literature, extracts obtained from the spike inflorescences of Prunella vulgaris have antitumor activity. 

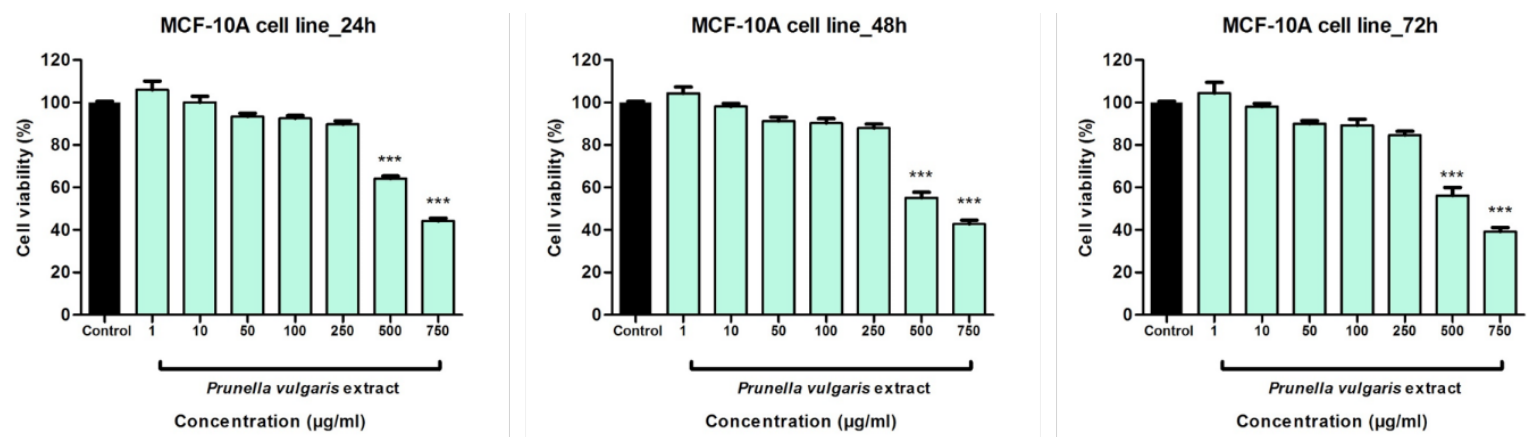

Fig. 3. In vitro effects of Prunella vulgaris extract $(1,10,50,100,250,500$ and $750 \mu \mathrm{g} / \mathrm{mL})$ on MCF-10A non-tumorigenic breast epithelial cell line at 24,48 and $72 \mathrm{~h}$ post-stimulation determined by Alamar blue technique. (Results are presented as mean \pm SD. Experiments were performed in triplicate) $(* p<0.05 ; * * p$ $<0.01 ; * * \mathrm{p}<0.001 \mathrm{vs}$ control calculated by One-way ANOVA followed by Dunnett's post-test).
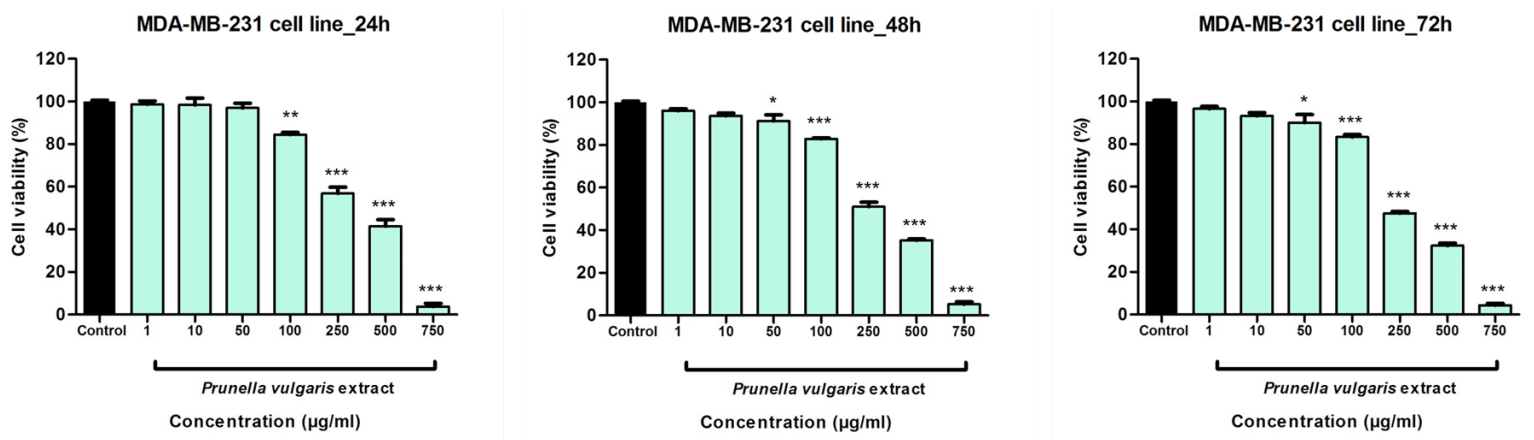

Fig. 4. In vitro effects of Prunella vulgaris extract $(1,10,50,100,250,500$ and $750 \mu \mathrm{g} / \mathrm{mL})$ on MDAMB-231-human breast adenocarcinoma cell line at 24,48 and $72 \mathrm{~h}$ post-stimulation determined by Alamar blue technique. (Results are presented as mean \pm SD. Experiments were performed in triplicate) $(* \mathrm{p}$ $<0.05 ; * * \mathrm{p}<0.01 ; * * * \mathrm{p}<0.001$ vs control calculated by One-way ANOVA followed by Dunnett's post-test).

These effects were found in the in vitro study, however, a higher concentration of active principles (rosmarinic acid) is needed to highlight the antitumor action of spike inflorescence, but efficient concentrations are improbable in vivo. Due to the high concentration of phenolic compounds, the spike inflorescence of Prunella vulgaris L. exhibits antioxidant action. The active compounds can directly inhibit the growth and proliferation of cancer cells (19-24). The present study has demonstrated that the extract (concentrated aqueous solution after initial extraction with methanol) from the spike inflorescence of Prunella vulgaris L. (collected from Romania) presents cytotoxic and anti-migratory potential in a dose and time dependent manner on the tested breast adenocarcinoma cell line, namely MDA-MB-231 while affecting less the non-tumorigenic breast epithelial cells.

Phenolic compounds (from the spike inflorescence), namely flavonoids, anthocyanins and phenolcarboxylic acids have antioxidant activities $(25,26)$. Phenolic compounds, as secondary metabolites of plants that can be found in abundance in plant sources, have pharmacological profiles of interest. In addition to the antioxidant action, their antibacterial activity can be exploited therapeutically with a minimum of side effects. This effect is described for all phenolic phytocompounds, but is intensively studied 


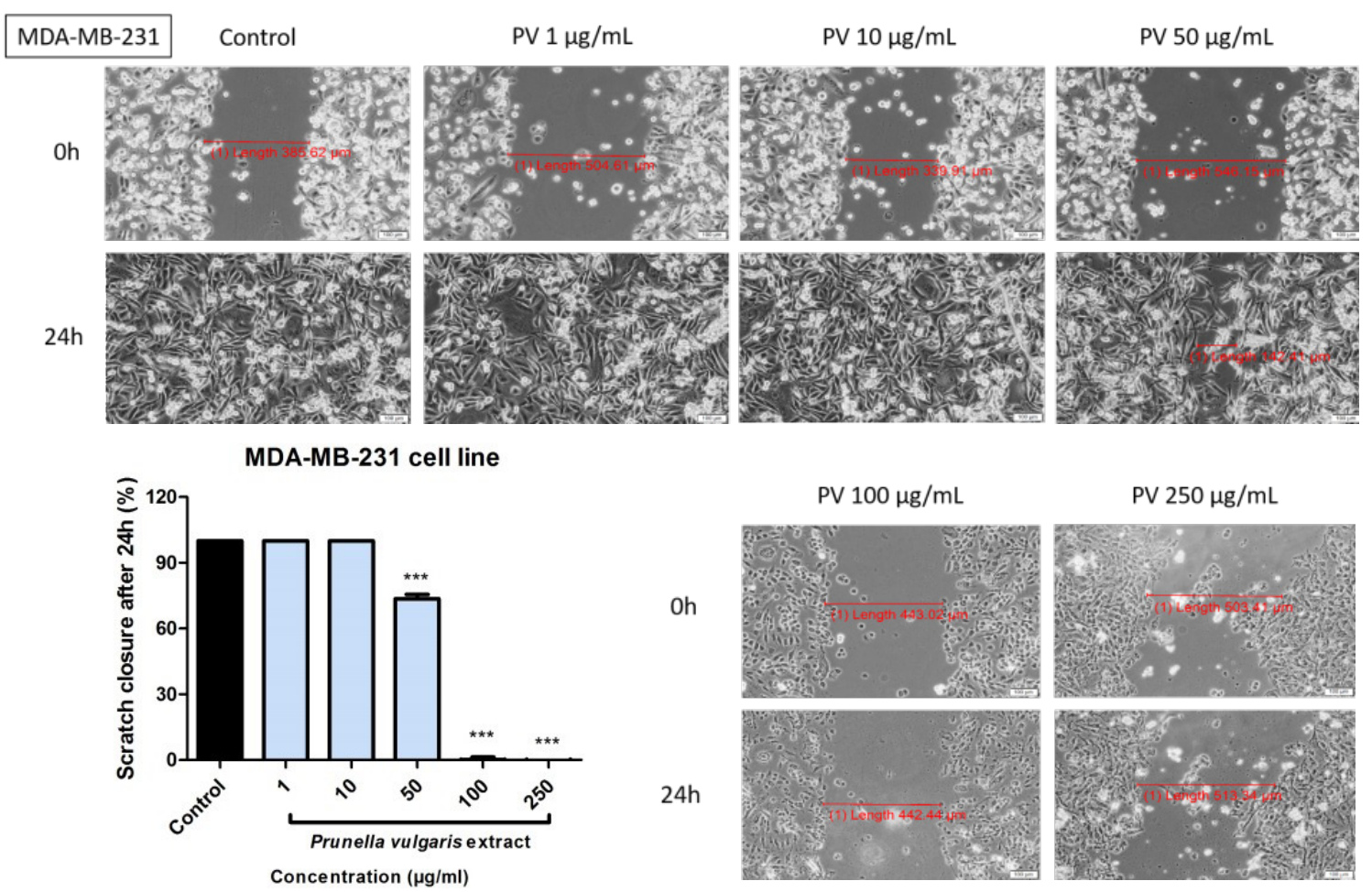

Fig. 5. Anti-migratory effect of Prunella vulgaris extract $(1,10,50,100$ and $250 \mu \mathrm{g} / \mathrm{mL})$ on MDA-MB-231human breast adenocarcinoma cell line. Images were taken by light microscopy at 10X magnification at $0 \mathrm{~h}$ and $24 \mathrm{~h}$ post-stimulation. The bar graph represents the percentage of scratch closure after $24 \mathrm{~h}$ compared to the starting point of the experiment (0h). One-way ANOVA test followed by Dunnett's multiple comparison test was used for comparison among the groups $(* \mathrm{p}<0.05 ; * * \mathrm{p}<0.01 ; * * * \mathrm{p}<0.001$ vs. Control-cells stimulated with the solvent DMSO).

for phenol-carboxylic acids, such as rosmarinic acid, which is present in the studied extracts (7). According to the literature, the methanolic extract of Prunella vulgaris L. has been shown to have significant antibacterial action. In vitro experiments have indicated that it has inhibitory activity on Gram-positive bacteria (8). However, our experiments show an antibacterial action of almost equal intensity on Gram-negative bacteria, both on standard strains and on clinical isolates (Pseudomonas aeruginosa, Klebsiella pneumoniae, Providencia stuartii). Aside already published data this makes us conclude that in methanol extracts, the antibacterial effect is achieved mostly because of the methanol itself and to a lesser extent by the extracted active compounds (27).

The antimicrobial action is influenced by the plant part taken into the study, the concentration of active principles and the type of solvent used. The most intense activity was presented by the more concentrated extract of spike inflorescence. This is due to variations in the composition of bioactive phenolic compounds, such as rosmarinic acid, ursolic acid and oleanolic acid, with the highest concentrations in full-flowering stage (28). Its antimicrobial action is dose and extraction type dependent. This was also found 
in other studies, methanolic extracts presenting more potent antimicrobial activity $(29,30)$. Our results showed that Gram negative bacteria were less susceptible to Prunella vulgaris L. extracts, but without significant differences among the representative species. Mahboubi et al. suggested that antibacterial activity is not directly related to the phenolic acid content (29), but rather to the flavonoid content (31). Nevertheless, phenolic acids such as rosmarinic acid enhance the activity of antibiotics against bacteria and provide a better time kill kinetics (32). Overall, our results support the positive biological activity potential of Prunella vulgaris L.

\section{Conclusions}

The methanolic extract of the species Prunella vulgaris L. (spike inflorescence) demonstrated a dose-dependent antitumor and antibacterial activity, including multidrug resistant strains. In vitro studies show a biological activity that may be the basis for the selection of compounds that are present in the extract to be subsequently tested in vivo, in order to determine the pharmacokinetic and pharmacodynamic properties in various animal models. In vitro screening may be the first step in identifying potential antitumoral and antibacterial compounds to be evaluated for appropriate test batteries for their biological activity.

\section{Acknowledgments}

This work was partly supported by George Emil Palade University of Medicine, Pharmacy, Science, and Technology of Târgu Mureș Research Grant number 294/5/14.1.2020.

\section{Author Contributions}

Conceptualization: A.G., C.E.V., R.S. and L.D.M.; Data curation, C.E.V., C.D., I.Z.P., Cr.D. and A.M.; Formal analysis: A.G. and R.E.D.; Methodology: A.G., R.S., R.E.D., I.Z.P., C.D.,
Cr.D., A.M. and L.V.; Supervision: L.D.M.; Validation: L.V. and L.D.M.; Writing - original draft: A.G., R.S. and A.M.; Writing - review \& editing: C.E.V., A.M., L.V. and L.D.M. All authors have read and agreed to the published version of the manuscript.

\section{Conflicts of Interest}

The authors declare no conflict of interest.

\section{References}

1. Pinkas M, Trotin F, Peng M, Torck M. Use, chemistry and pharmacology of the Chinese medicinal plants. Fitotherapia. 1994. 55:343-53.

2. Wagner H, Bauer R, Melchart D, Staudinger A, Spica prunellae, Xiacukao in Chromatographic Fingerprint Analysis of Herbal Medicines, Thin Layer and High Performance Liquid Chromatography of Chinese Drugs. Vol. 4, Springer International Publishing Switzerland 2016, pp. 225-237; ISBN 978- 3-319-32328-2. DOI: 10.1007/978-3-319-32328-2_22

3. Duke J. Prunella vulgaris. Handbook of Edible Weeds, 2001, CRC, p.158.

4. Gao W, Xu HLYLYLY. Root extract of Prunella vulgaris inhibits in vitro and in vivo carcinogenesis in MCF-5 human breast carcinoma via suppression of angiogenesis, induction of apoptosis, cell cycle arrest and modulation of PI3K/AKT signalling pathway. J Buon. 2019 Mar-Apr; 24(2):549-554.

5. Su YC, Lin IH, Siao YM, Liu CJ, Yeh CC. Modulation of the Tumor Metastatic Microenvironment and Multiple Signal Pathways by Prunella vulgaris in Human Hepatocellular Carcinoma. Am J Chin Med. 2016;44(4):83549. DOI: 10.1142/S0192415X16500464

6. Rasool R, Ganai BA, Kamili AN, Akbar S, Masodd A. Antioxidant and Antibacterial Activities of Extracts from Wild and in Vitro- Raised Cultures of Prunella Vulgaris L., Medicinal and aromatic plant science and biotechnology. 2010;4(1):20-7.

7. Mahboubi M., Mahboubi A., Kazempour N., The antimicrobial activity of Prunella vulgaris extracts. Herb Pol. 2015;61(1):31-8. DOI: 10.1515/hepo-2015-0008

8. Psotová J, Kolár M, Sousek J, Svagera Z, Vicar J, Ulrichová J. Biological Activities of Prunella vulgaris Extract. Phytother Res. 2003 Nov;17(9):1082-7. DOI: 
$10.1002 / p t r .1324$

9. Komal S, Kazmi SAJ, Khan JA, Gilani MM. Antimicrobial activity of Prunella Vulgaris extracts against multi-drug resistant Escherichia Coli from patients of urinary tract infection. Pak J Med Sci. 2018 MayJun;34(3):616-20. DOI: 10.12669/pjms.343.14982

10. Roh KB, Park D, Jung E. Inhibitory Effects of Prunella vulgaris L. Extract on 11ß-HSD1 in Human Skin Cells. Evid Based Complement Alternat Med. 2018 Oct 4;2018:1762478 DOI: 10.1155/2018/1762478

11. Xu Y, Jiang Z, Ji G, Liu J. Inhibition of bone metastasis from breast carcinoma by rosmarinic acid. Planta Med. 2010 Jul;76(10):956-62. DOI: 10.1055/s-00291240893

12. Benedec D, Hanganu D, Oniga I, Tiperciuc B, Olah NK, Raita O, et al. Assessment of rosmarinic acid content in six Lamiaceae species extracts and their antioxidant and antimicrobial potential. Pak J Pharm Sci. 2015 Nov;28(6 Suppl):2297-303.

13. Toiu A, Vlase L, Vodnar DC, Gheldiu AM, Oniga I. Solidago graminifolia L. Salisb. (Asteraceae) as a valuable source of bioactive polyphenols: HPLC profile, in vitro antioxidant and antimicrobial potential. Molecules. 2019 Jul 23;24(14). pii: E2666. DOI: 10.3390/ molecules 24142666

14. Methods for Dilution Antimicrobial Susceptibility Tests for Bacteria That Grow Aerobically, 11th Edition. 2018 https://clsi.org/standards/products/microbiology/ documents $/ \mathrm{m} 07$

15. Moacă EA, Pavel IZ, Danciu C, Crăiniceanu Z, Minda $\mathrm{D}$, Ardelean F, et al. Romanian Wormwood (Artemisia absinthium L.): Physicochemical and Nutraceutical Screening. Molecules. 2019 Aug 25;24(17). pii: E3087. DOI: $10.3390 /$ molecules 24173087

16. Danciu C, Muntean D, Alexa E, Farcas C, Oprean C Zupko I, et al. Phytochemical Characterization and Evaluation of the Antimicrobial, Antiproliferative and Pro-Apoptotic Potential of Ephedra alata Decne. Hydroalcoholic Extract against the MCF-7 Breast Cancer Cell Line. Molecules. 2018 Dec 20;24(1). pii: E13. DOI: $10.3390 /$ molecules 24010013

17. Man A, Santacroce L, Iacob R, Mare AD, Man L. Antimicrobial activity of six essential oils against a group of human pathogens: A comparative study. Pathogens. 2019 Jan 28;8(1). pii: E15. DOI: 10.3390/pathogens 8010015

18. Grama L, Man A, Muntean DL, Gâz Florea ȘA, Boda
F, Curticăpean A. Antibacterial activity of some saturated polyoxotungstates. Rev Romana Med Lab. 2014;22(1):111-8. DOI: 10.2478/rrlm-2014-0007

19. Zhu J, Zhang W, Zhang Y, Wang Y, Liu M, Liu Y. Effects of Spica prunellae on caspase-3-associated proliferation and apoptosis in human lung cancer cells in vitro. J Cancer Res Ther. 2018;14(4):760-3. DOI: 10.4103/jcrt.JCRT_1289_16

20. Hwang YJ, Lee EJ, Kim HR, Hwang KA. In vitro antioxidant and anticancer effects of solvent fractions from prunella vulgaris var. lilacina. BMC Complement Altern Med. 2013 Nov 9;13:310. DOI: 10.1186/14726882-13-310

21. Qiang Z, Ye Z, Hauck C, Murphy PA, McCoy JA, Widrlechner MP, Reddy MB, Hendrich S. Permeability of rosmarinic acid in Prunella vulgaris and ursolic acid in Salvia officinalis extracts across Caco-2 cell monolayers, J Ethnopharmacol. 2011 Oct 11;137(3):1107-12. DOI: $10.1016 /$ j.jep.2011.07.037

22. Feng L, Jia XB, Jiang J, Zhu MM, Chen Y, Tan XB, Shi F. Combination of active components enhances the efficacy of Prunella in prevention and treatment of lung cancer Molecules. 2010 Nov 4;15(11):7893-906. DOI: $10.3390 /$ molecules 15117893

23. Su Y, Lin IH, Siao YM, Liu CJ, Yeh CC. Modulation of the Tumor Metastatic Microenvironment and Multiple Signal Pathways by Prunella vulgaris in Human Hepatocellular Carcinoma. Am J Chin Med. 2016;44(4):83549. DOI: $10.1142 / \mathrm{S} 0192415 X 16500464$

24. Feng L, Au-Yeung W, Xu YH, Wang SS, Zhu Q, Xiang P. Oleanolic acid from Prunella Vulgaris L. induces SPC-A-1 cell line apoptosis via regulation of Bax, Bad and Bcl-2 expression. Asian Pac J Cancer Prev. 2011;12(2):403-8.

25. Mohsen SM, Ammar AS. Total phenolic contents and antioxidant activity of corn tassel extracts. Food Chem. 2009;112(3):595-8. DOI: $10.1016 / j$.foodchem.2008.06.014

26. Feng L, Jia X, Zhu MM, Chen Y, Shi F. Antioxidant Activities of Total Phenols of Prunella vulgaris L. in Vitro and in Tumor-bearing Mice. Molecules. 2010 Dec 10;15(12):9145-56. DOI: 10.3390/molecules 15129145

27. Man A, Gâz Florea ȘA, Mare AD, Berta L. Effects of low-molecular weight alcohols on bacterial viability. Rev Romana Med Lab. 2017;25(4):335-43. DOI: 10.1515/rrlm-2017-0028 
28. Chen Y, Zhu Z, Guo Q, Zhang L, Zhang X. Variation in concentrations of major bioactive compounds in Prunella vulgaris L. related to plant parts and phenological stages. Biological Research. 2012;45(2):171-5. DOI: $10.4067 / \mathrm{S} 0716-97602012000200009$

29. Mahboubi M, Mahboubi A, Kazempour N. The antimicrobial activity of Prunella vulgaris extracts. Herba Polonica. 2015 Mar 1;61(1):31-8. DOI: 10.1515/hepo2015-0008
30. Komal S, Kazmi SAJ, Khan JA, Gilani MM. Antimicrobial activity of Prunella Vulgaris extracts against multi-drug resistant Escherichia Coli from patients of urinary tract infection. Pak J Med Sci. 2018;34(3):61620. DOI: $10.12669 /$ pjms. 343.14982

31. Xie Y, Yang W, Tang F, Chen X, Ren L. Antibacterial activities of flavonoids: structure-activity relationship and mechanism. Curr Med Chem. 2015;22(1):132-49. DOI: $10.2174 / 0929867321666140916113443$ 